\title{
TARGETING AND INFORMAL INSURANCE
}

\author{
ETHAN LIGON
}

\begin{abstract}
The standard method of testing for efficient risk-sharing in village economies (Townsend, 1994) doesn't allow one to identify vulnerable households, only to make statements about the average risk in the village, or of sub-groups identifiable on the basis of observables. Here, by working directly with inter-household consumption correlations we're able to identify households which are probably exposed to unusually high amounts of idiosyncratic risk. An obvious use for this identifying information involves targeted interventions to help those households. However, the effectiveness of these interventions depends on the market imperfections which exposes those households to idiosyncratic risk to begin with. Using data from the Indian ICRISAT villages, we trace out the expected outcomes of targeted income transfers given several different hypotheses regarding why some households bear idiosyncratic risk.
\end{abstract}

\section{INTRODUCTION}

To be successful, policies meant to target assistance to poor, vulnerable households must do a reasonably good job of identifying the target population. Although here are a number of well-known measurement difficulties involved in this sort of identification, methods for identifying poor households are better developed than are methods for identifying households which bear disproportionate risk, beginning with an appropriate measure of risk.

The usual measure of poverty is just some scalar measure of wealth, perhaps adjusted for household composition or other circumstances, but still just a number. In contrast, the risk a household faces is related to an entire distribution of possible outcomes. Thus, while measures of poverty focus on summarizing a distribution across households, a measure of risk must summarize a distribution for each household, as well as providing a population summary.

Our approach here is motivated by some of the same concerns that have motivated other researchers to try and directly extend traditional measures of static poverty to a dynamic environment with uncertainty. Of particular note in this connection is Ravallion (1988) who, with a similar motivation and the same dataset that we will use, tries and distingush between "transitory" and "permanent" components of poverty, ${ }^{1}$ to better understand the effects of uncertainty on expected poverty.

In this paper, we provide a natural, cardinal measure of risk which is consistent with the ordinal notion of risk developed in Rothschild and Stiglitz (1970). We give a simple method for decomposing this measure of risk into risk which is attributable to aggregate shocks, observable idiosyncratic shocks, and unobservable shocks. As a by-product, we develop an estimator for the kinds of risk-sharing regressions developed by Townsend (1994) and

Date: October 30, 2003.

${ }^{1}$ Jalan and Ravallion (2000) do something similar, but with Chinese data; Dercon and Krishnan (2000) use Ethiopian data to measure households' movements in and out of poverty; and Baulch and Hoddinott (2000) provide a nice survey of the young but rapidly growing literature on dynamic poverty. 
Deaton (1990) which allows consistent hypothesis testing and inference even in the presence of cross-sectional correlation of unspecified form.

We apply our techniques to a dataset from the Indian ICRISAT villages explored by Townsend (1994) and many others. This Indian data is of particular interest because there seems to be general agreement that these villages display a great deal of risk-sharing, yet there is relatively little direct evidence on just how this risk-sharing is accomplished. Information on risk-sharing networks can be gleaned from estimated correlations between household consumptions (or correlations in residuals from some prediction equation). We use this technique to identify, for example, two quite distinct risk-sharing groups in Aurepalle, one composed chiefly of households with substantial land-holdings, and the other of households with little or no land.

The remainder of this Chapter is organized as follows. In Section 2, we provide a precise definition of risk used in this paper. The measure we provide is cardinal, and is consistent with the ordinal approach taken by Rothschild and Stiglitz (1970). This same measure of risk is combined with a measure of poverty to construct a measure of overall vulnerability in Ligon and Schechter (2003). In Section 3, we provide methods to estimate the risk borne by households, and show that this measure can be easily decomposed into risk from various sources. Once one has identified households which one thinks may bear large amounts of risk, one may wish to ameliorate this risk. In Section 4 we discuss the problems that may arise from acting on these good intentions. Since the intervention of an outsider may be perceived by the community as yet another sort of shock, existing mechanisms for sharing risk within the village may also serve to undo targeted transfers. We consider the consequences of targeting transfers to villages under a sequence of different assumptions regarding existing markets and institutions. Section 5 concludes.

\section{Defining Risk}

We take a utilitarian approach to defining a measure of the risk households face. Suppose there to be a finite population of households indexed by $i=1,2, \ldots, n$, and let $\omega \in \Omega$ denote the state of the world. We focus on the distribution of household $i$ 's consumption expenditures, $c^{i}(\omega)$, rather than measures of income or wealth on the grounds that these kinds of expenditures are what most directly determines household welfare. To measure risk, for each household we first choose some strictly increasing, weakly concave function $U^{i}: \mathbb{R} \rightarrow \mathbb{R}$ mapping consumption expenditures into the real line. Given the function $U^{i}$, we define the risk faced by the household by the function

$$
R^{i}=U^{i}\left(\mathrm{E} c^{i}\right)-\mathrm{E} U^{i}\left(c^{i}\right) .
$$

Taking expectations of an increasing, concave function of consumption expenditures has the effect of making risk depend not only on the mean of a household's consumption, but also on variation in consumption. Take, for example, the case in which consumption expenditures are bounded above by some $b$, and where we take $U^{i}(c)=-(c-b)^{2}$. In this case, the risk facing a household is simply equal to the variance of consumption expenditures.

The measure $R^{i}$, which measures the risk faced by household $i$, is consistent with the ordinal measures of risk proposed by Rothschild and Stiglitz (1970) (though any monotone transformation of $R^{i}$ would do as well). Further, this risk measure can usefully be further decomposed into two distinct measures of risk, one aggregate, the other idiosyncratic. Let 
$\mathrm{E}\left(c^{i} \mid \bar{c}\right)$ denote the expected value of consumption $c^{i}$ conditioned on knowledge of aggregate consumption $\bar{c}$. Then we can rewrite the risk facing household $i$ as

$$
R^{i}=\left[U^{i}\left(\mathrm{E} c^{i}\right)-\mathrm{E} U^{i}\left(\mathrm{E}\left(c^{i} \mid \bar{c}\right)\right)\right]+\left[\mathrm{E} U^{i}\left(\mathrm{E}\left(c^{i} \mid \bar{c}\right)\right)-\mathrm{E} U^{i}\left(c^{i}\right)\right] .
$$

Here the first term expresses the aggregate risk facing the household, while the second filters out the aggregate component of risk to leave only the component of idiosyncratic risk. ${ }^{2}$

Of course the notation here is intentionally chosen to evoke comparisons with utility functions. If in fact our functions $\left\{U^{i}\right\}$ coincide with households' von Neumann-Morgenstern momentary (indirect) utility functions, then we can interpret our measure of risk as the loss of utility experienced from consumption risk. Further, If one were to adopt a utilitarian notion of welfare for some population of $n$ households, then in principle one could use the set of functions $\left\{U_{i}\right\}$ in the objective function of a social planner, as in Townsend (1994); in this case a social planner who maximizes a weighted sum of these functions subject to some aggregate resource constraint would implicitly allocate resources so as to eliminate the idiosyncratic component of risk.

Despite the notation, our proposed procedure of maximizing the sum of the expected values of concave functions of expenditures need not be interpreted as a utilitarian social welfare function. One of several possible alternative interpretations would have a paternalistic donor or NGO choose some concave function, with the shape of the function reflecting the donor's preferences over the distribution and uncertainty of consumption expenditures. One happy consequence of this sort of paternalism is that it's not necessary to be able to measure individual households' utility functions.

As a simple example, consider an environment with no uncertainty, and suppose that a donor with budget $B$ wishes to make income transfers to a population of $n$ households in such a way as to minimize poverty, as measured by the Foster et al. (1984) poverty index. This is equivalent to choosing functions $\left\{U^{i}\right\}$ such that

$$
U^{i}(c)=\frac{|c-z|^{\alpha}}{\alpha} \operatorname{sgn}(c-z) .
$$

To interpret this as a measure of poverty, we may interpret $z$ as a poverty line, and $\alpha$ is a parameter which could be chosen by the donor to place more or less emphasis on the consumption of the very poor.

Now suppose that this same function is used in an environment in which households face shocks which make their consumption expenditures uncertain. As a consequence, $U^{i}(c)$ is itself a random variable. What, then, should the objective of the donor be? One natural possibility (and the one which we'll pursue here) would be for the donor to seek to minimize expected poverty, and now the functions $\left\{U^{i}\right\}$ should be chosen to reflect the donor's preferences over both the distribution of consumption expenditures and over the risk that households face. The properties of (1) for evaluating the distribution of income are well understood when there's no uncertainty. However, if a donor were to use this function to evaluate expected poverty, what would the consequences be?

First, note that this function is nondecreasing in $c^{i}$ for all real values of $c, z$, and $\alpha$; a donor with these preferences always (weakly) prefers any given household to have more,

\footnotetext{
${ }^{2}$ Ravallion (1988) uses a different decomposition in order to distinguish between permanent and transitory poverty.
} 
rather than less, consumption. Second, note that (1) is concave if either of the following conditions hold:

(1) $\alpha>1$ and $0 \leq c \leq z$;

(2) $\alpha<1$ and $0 \leq z \leq c$.

The first case, under certainty, is considered by Foster et al. (1984), while Ravallion (1988) considers the same case under uncertainty. The second case really changes the function considered by these authors into a standard HARA utility function, with a coefficient of relative risk aversion equal to $(\alpha-1) \frac{c}{z-c}$. As long as this quantity is positive, then the donor has a preference against exposing households to needless risk.

In the usual analysis (with no uncertainty), one's choice of the parameter $\alpha$ reflects one's sensitivity to inequality in distribution. As one might expect, in an environment with uncertainty, the choice of this parameter also has important consequences for the qualitative nature of the donor's preferences over risk. In particular, when $c<z$ and $\alpha>1$ this index implicitly supposes that households with high levels of expenditures are more sensitive to risk than are poorer households, in the sense that if no household currently faced any consumption risk, but the donor had to assign a fair bet of fixed size to some household in the population, then it would prefer to assign that bet to a household with lower consumption, ceteris paribus. Interpreting $U^{i}$ as a utility function, this is just a statement to the effect that households have increasing absolute risk aversion. Of course, this is precisely the reverse of what is usually assumed in research on households' tolerance of risk (for an early argument, see Arrow (1965)). To put the matter concisely, any donor who seeks to minimize the expected value of the Foster-Greer-Thorbecke poverty measure (minus one times the function defined in (1), with $\alpha>1$ and $0 \leq c \leq z$ ) implicitly assumes that households with low consumption are better able to tolerate risk than are better-off households. A donor who wished to assign more risk to wealthier households should choose $\alpha<1$ and $z \leq c$, thus maximizing a standard utilitarian social welfare function, with HARA utility functions.

\section{MEASURING Risk}

Among recent papers on risk-sharing, Townsend (1994) has arguably been the most influential. Assuming that agents are risk averse, with von Neumann-Morgenstern preferences with an exponential momentary utilility function, Townsend derives the consumption function for each household in a village economy, which with exponential utility and complete markets can be written as a linear function of village aggregate consumption.

Thus, to test the hypothesis of complete markets, Townsend regresses deviations of household consumption from the village average on a set of household specific fixed effects and some set of other right hand side variables. Under the null hypothesis such other variables shouldn't have any additional ability to explain household consumption. Townsend rejects the null hypothesis; various measures of household income seem to be related to the residual from Townsend's consumption function. Nonetheless, the magnitude of the coefficients he estimates seem to be small, at least relative to some researchers' priors, and it seems fair to say that Townsend's research has convinced many people that consumption insurance is very important in at least three Indian villages.

Still, like much good empirical research, Townsend's paper raises more questions than it answers. He has, after all, rejected the most coherent theoretical model we have of village allocation - what should the complete markets model be replaced with? To answer a model 
with incomplete markets is fatuous, as this class includes far more models than it excludes. Also, if one takes as given that households are doing a great deal of consumption smoothing, then that raises the question of what sort of specific institutions are being employed at the village level to accomplish this smoothing. Certainly households aren't participating in some spanning set of contingent claims markets in any formal sense, and one wonders what less formal mechanisms are taking the place of these textbook markets.

Here we take a different approach to measuring risk-sharing which focuses on accurately inferring and accounting for the different kinds of risks households face, rather than on hypothesis testing. Nonetheless, a strong parallel with Townsend's regression emerges. In addition, though this paper offers no conclusive evidence on either of these questions, we add some new information with which to inform the debate. First, we point out a qualification to the conclusions that many (though not Townsend himself) have drawn from Townsend's research - namely, that although in each of the three villages Townsend works with household income isn't very highly correlated with consumption residuals (the main conclusion from Townsend's test), neither is it the case that household consumptions are very highly correlated with each other, which seems at odds with the idea that there's a great deal of consumption insurance in these villages. Where there's little insurance, the search for institutions which provide insurance seems less pressing. Second, by working directly with inter-household correlations, we're able to identify households that do have significantly correlated consumptions. In only one of the three villages we work with (Aurepalle) do there seem to be many such households; we turn our attention to the problem of trying to identify factors which help to predict whether a given household will be well-insured by this measure or not.

Our approach to measuring risk in the ICRISAT villages begins with an effort to operationalize the measures of risk developed in the previous section. We begin by supposing, as is usual in the literature on consumption-smoothing, that consumption is measured with error. Let $z_{t}$ denote a vector of possibly time-varying village characteristics, let $x_{t}^{i}$ denote a vector of observed, time-varying household characteristics, and let $c_{t}^{i}$ denote the actual consumption of household $i$ at date $t$, and let $\tilde{c}_{t}^{i}=c_{t}^{i}+\epsilon_{t}^{i}$ denote observed consumption, where $\epsilon_{t}^{i}$ is some measurement error, with the property that $\mathrm{E}\left(\epsilon_{t}^{i} \mid z_{t}, x_{t}^{i}\right)=0$ and $\mathrm{E}\left(\epsilon_{t}^{i} \mid c_{t}^{i}\right)=0$.

In the presence of measurement error, using observed consumption to measure risk as in Section 3 would lead the analyst to confute measurement error with idiosyncratic risk. To avoid this problem, we further decompose our measure of idiosyncratic risk into risk which can be attributed to variation in observed household characteristics $x_{t}^{i}$ and a risk which can't be explained by such variation, but which is due instead to variation in unobservables and to measurement error in consumption. Thus, rewriting the expression for risk yields

$$
\begin{aligned}
R^{i}= & {\left[U^{i}\left(\mathrm{E} c_{t}^{i}\right)-\mathrm{E} U^{i}\left(\mathrm{E}\left(c_{t}^{i} \mid z_{t}\right)\right)\right] \quad(\text { Aggregate risk) }} \\
+ & {\left[\mathrm{E} U^{i}\left(\mathrm{E}\left(c_{t}^{i} \mid z_{t}\right)\right)-\mathrm{E} U^{i}\left(\mathrm{E}\left(c_{t}^{i} \mid x_{t}^{i}, z_{t}\right)\right)\right] \quad \text { (Explained idiosyncratic risk) } } \\
+ & {\left[\mathrm{E} U^{i}\left(\mathrm{E}\left(c_{t}^{i} \mid x_{t}^{i}, z_{t}\right)\right)-\mathrm{E}^{i}\left(c_{t}^{i}\right)\right] . \quad \text { (Unexplained risk \& measurement error) } }
\end{aligned}
$$

Two additional steps are required before one can actually use data to compute the risk facing a household. First, one must choose the functions $\left\{U^{i}\right\}$. Second, one must devise a way to estimate the conditional expectations which figure in our risk measure. Here, we choose the risk evaluation function to take the simple form $U^{i}(c)=\left(c^{1-\gamma}-1\right) /(1-\gamma)$ for some parameter $\gamma>0$; as gamma increases, the function $U^{i}$ becomes increasingly sensitive 
to risk. We assume that $\mathrm{E}\left(c_{t}^{i} \mid z_{t}, x_{t}^{i}\right)=\alpha^{i}+\eta_{t}+x_{t}^{i} \beta$, where $\theta=\left(\alpha^{i}, \eta_{t}, \beta^{\prime}\right)$ is a vector of unknown parameters, to be estimated.

We estimate the unconditional expectation of household $i$ 's consumption by $\operatorname{E} c_{t}^{i}=\frac{1}{T} \sum_{t=1}^{T} c_{t}^{i}$. For the present application, we wish to choose $\theta$ so as to optimally predict $c_{t}^{i}$ in a least-squares sense. In the presence of measurement error, choosing parameters to predict consumption has the consequence that our estimates of total risk will not be unbiased. However, given our assumptions on the measurement error process $\epsilon_{t}^{i}, \mathrm{E}\left(c_{t}^{i} \mid z_{t}, x_{t}^{i}\right)=\mathrm{E}\left(\tilde{c}_{t}^{i} \mid z_{t}, x_{t}^{i}\right)$, measurement error in consumption expenditures will influence only our measure of unexplained risk. This last measure will be incorrect by the difference

$$
\mathrm{E} U^{i}\left(\tilde{c}_{t}^{i}\right)-\mathrm{E} U^{i}\left(c_{t}^{i}\right)
$$

while our measures of aggregate and explained idiosyncratic risk will not be biased by this sort of measurement error.

Our parameterization of $\mathrm{E}\left(c_{t}^{i} \mid z_{t}, x_{t}^{i}\right)$ suggests the linear estimating equation

$$
\tilde{c}_{t}^{i}=\alpha^{i}+\eta_{t}+x_{t}^{i} \beta+v_{t}^{i}
$$

where the conditioning information $\left(z_{t}, x_{t}^{i}\right)$ is understood to include the knowledge of the date and of the identity of the household, ${ }^{3}$ where $v_{t}^{i}$ is a disturbance term equal to the sum of both measurement error in consumption as well as prediction error, and where the household fixed effects $\alpha^{i}$ are restricted to sum to zero.

Our focus on risk-sharing strongly suggests that the disturbances $\left\{v_{t}^{i}\right\}$ may be correlated across households. This follows, for example, if a subset of the population is engaged in an otherwise perfect risk-sharing scheme. We assume that the cross-sectional correlation is governed by a time-invariant matrix $\Sigma=\left[\operatorname{cov}\left(v_{t}^{i}, v_{t}^{j}\right)\right]$. Accordingly, we first construct point estimates of the parameters of (2) using ordinary least squares. Next, following Newey and West (1987), we use the estimated residuals $\left\{\hat{v}_{t}^{i}\right\}$ to estimate $X^{\prime}\left(\Sigma \otimes I_{T}\right) X$, where the matrix $X$ denotes the regressors employed in estimation, and where the $(i, j)$ element of $\Sigma$ is estimated by $\hat{\Sigma}=\frac{1}{T} \sum_{t=1}^{T} \hat{v}_{t}^{i} \hat{v}_{t}^{j}$. For this just identified estimator, the estimated covariance matrix of our parameter estimates is given by $\left(X^{\prime} X\right)^{-1} X^{\prime}\left(\hat{\Sigma} \otimes I_{T}\right) X\left(X^{\prime} X\right)^{-1}$. This estimator of variance is consistent even in the presence of unspecified cross-sectional correlation, so long as this correlation is unchanging over time.

Using data on household consumption and income for the three Indian ICRISAT villages identical to that used by Townsend, we've estimated (2), using household income for the right-hand side variable $x_{t}^{i}$. Point estimates for the associated parameter $\beta$ along with estimated standard errors are presented in the first lines of Table 1. The point estimates in this table very nearly replicate results reported in Townsend (1994) ${ }^{4}$ As one might expect, in two of the three villages the OLS standard errors reported by Townsend are lower than are our estimates, as we correct these estimates for cross-sectional correlation in a way Townsend

\footnotetext{
${ }^{3}$ Thus, $\left\{\eta_{t}\right\}$ captures the influence of changes in aggregates, and $\left\{\alpha^{i}\right\}$ captures the influence of fixed household characteristics on predicted household consumption.

${ }^{4}$ The relevant results from Row 1 of Table XIII(c) of Townsend's paper are

\begin{tabular}{cccc} 
& Aurepalle & Shirapur & Kanzara \\
\hline$\beta$ & 0.1362 & 0.0830 & 0.1398 \\
& $(0.0265)$ & $(0.0218)$ & $(0.0270)$
\end{tabular}

We would replicate Townsend's point estimates exactly, except that we've used data only for households observed continuously over the period 1976-81.
} 
did not. However, in one village (Shirapur), our estimated standard errors are actually slightly smaller than are Townsend's estimates, and despite the correction, household income continues to have a pronounced, significant effect on household consumption in every village.

\begin{tabular}{l|rrr}
\hline \hline & Aurepalle & Shirapur & Kanzara \\
\hline$\beta$ & 0.1075 & 0.1015 & 0.1417 \\
& $(0.0332)$ & $(0.0237)$ & $(0.0363)$ \\
\hline Aggregate Risk & 26.2984 & 1.8888 & 6.6943 \\
Compensation & {$[17.6760,35.7046]$} & {$[0.9651,6.8974]$} & {$[4.3943,12.9619]$} \\
Idiosyncratic Risk & 1.9049 & 2.3958 & 3.5221 \\
Compensation & {$[0.2816,3.2486]$} & {$[0.5356,5.1289]$} & {$[0.5073,6.7310]$} \\
Unexplained Risk & 17.2996 & 30.8564 & 15.0921 \\
Compensation & {$[-0.3030,50.1978]$} & {$[-5.2433,72.1132]$} & {$[-13.2834,53.3856]$} \\
\hline \hline
\end{tabular}

TABLE 1. Risk compensation for different components of consumption risk. The first row reports point estimates for the coefficient associated with household income, in a regression of household consumption on income, a set of household fixed effects, and a set of time effects. Parenthetical numbers are the standard errors of these point estimates, taking into account possible crosssectional correlation in disturbances. Subsequent rows report estimates and bootstrapped confidence intervals for the average risk compensation required (in every period) to compensate each household for facing each particular source of risk.

With an estimate of $\mathrm{E}\left(c_{t}^{i} \mid z_{t}, x_{t}^{i}\right)$ in hand, we proceed to estimate the different components of risk. Following the suggestion of Arrow (1965), we choose the parameter $\alpha=-1$, implying a relative risk aversion of two. However, rather than reporting a measure of risk denominated in utils, we find the certain transfer $b$ necessary to just compensate the household for the risk it faces. So, for example, to measure the aggregate risk the household faces, we find some number $b$ satisfying

$$
U^{i}\left(\mathrm{E} c_{t}^{i}\right)=\mathrm{E} U^{i}\left(b+\mathrm{E}\left(c_{t}^{i} \mid z_{t}\right)\right)
$$

and similarly for explained idiosyncratic risk and unexplained risk. We call this transfer risk compensation. Both consumption expenditures and $b$ are denominated in 1975 Rupees; the mean of estimated risk compensations are presented in Table 1 by village and component.

From Table 1, the total risk faced by households in Aurepalle could be compensated by an annual per-household payment of between 27.42 and 44.771975 Rs (depending on whether or not unexplained risk is included or not). From the perspective of a wealthy donor, this is a rather small sum, between about $\$ 10.50$ and $\$ 17.50$ in current U.S. dollars. However, when compared to per household consumption expenditures of Rs. 787 in Aurepalle, the importance of risk springs into sharper focus: the average total risk compensation in Aurepalle amounts to between 7.6 and 12.3 per cent of consumption expenditures. Analogous figures for Shirapur are 0.9 and 7.1 per cent, and for Kanzara are 2.1 and 6.6 per cent.

Our largest estimate of risk compensation (12.3 per cent of average household expenditures in Aurepalle) seems considerable in welfare terms, but not enormous, particularly since much of this may be attributable to measurement error. In Shirapur and Kanzara estimates of explained risk compensations actually seem quite small. One explanation for may be that 
there's not actually a great deal of risk in the environment of these villages; an alternative is that households have developed effective means of reducing consumption risk, whether via risk-sharing, self-insurance, or some other sort of arrangement.

\begin{tabular}{l|rrr}
\hline \hline$\beta$ & Aurepalle & Shirapur & Kanzara \\
\hline$\beta$ & 1.0488 & 0.7014 & 1.1206 \\
& $(0.3465)$ & $(0.1838)$ & $(0.2811)$ \\
\hline Aggregate Risk & 30.4632 & 17.8811 & 19.0124 \\
Compensation & {$[10.8093,78.9837]$} & {$[8.3641,48.0137]$} & {$[11.3652,45.7730]$} \\
Idiosyncratic Risk & 11.6528 & 14.5646 & 12.2930 \\
Compensation & {$[-1.3890,20.9283]$} & {$[0.2103,33.0543]$} & {$[-1.4376,25.0382]$} \\
Unexplained Risk & 16.4296 & 76.0551 & 53.1372 \\
Compensation & {$[-14.8286,52.2384]$} & {$[49.3828,103.8923]$} & {$[-174.3121,221.1009]$} \\
\hline \hline
\end{tabular}

TABLE 2. Risk compensation for different components of income risk. The first row reports point estimates for the coefficient associated with household consumption, in a regression of income on household consumption, a set of household fixed effects, and a set of time effects. Parenthetical numbers are the standard errors of these point estimates, taking into account possible crosssectional correlation in disturbances. Subsequent rows report estimates and bootstrapped confidence intervals for the average risk compensation required (in every period) to compensate each household for facing each particular source of risk.

Table 2 is similar to Table 1, except that instead of measuring risk in consumption expenditures, it reports measures of compensation for income risk. Note that information on idiosyncratic consumption is used to predict income, so that (re-using the notation for parameters from above) we have $\mathrm{E}\left(x_{t}^{i} \mid z_{t}, \tilde{c}_{t}^{i}\right)=\alpha^{i}+\eta_{t}+\tilde{c}_{t}^{i}$, estimated as before. Comparison of these two tables is informative. Total income risk seems considerable across all three villages, amounting to 58.541975 Rs. in Aurepalle, 108.50 Rs. in Shirapur, and 84.44 Rs. in Kanzara. The three villages differ in interesting ways. Aggregate risk seems to be particularly important in Aurepalle, in both income and consumption - there appears to be little smoothing of aggregate consumption in this village. On the other hand, while there's considerable idiosyncratic risk in income, there's very little idiosyncratic risk in consumption, suggesting that mechanisms for sharing risk may be quite effective in Aurepalle. In Shirapur there's somewhat less aggregate income risk than in Aurepalle, but both aggregate and idiosyncratic consumption risk are negligible, suggesting that the village makes important use of some intertemporal technology, such as storage or transactions in credit markets outside the village. The possibility of this sort of financial integration means that the very small idiosyncratic risk in Shirapur may be due to village-level risk-sharing, or may alternatively be due to credit or insurance arrangements made outside the village. Kanzara is somewhat similar to Shirapur, in that both aggregate and idiosyncratic risk in consumption is considerably smaller than it is for income, which again implies the use of storage or credit, combined with some unidentified form of insurance against most idiosyncratic risk.

In order to shed some additional light on the mechanisms used to insure consumption in different villages, I've computed the simple correlation coefficients between the consumptions 

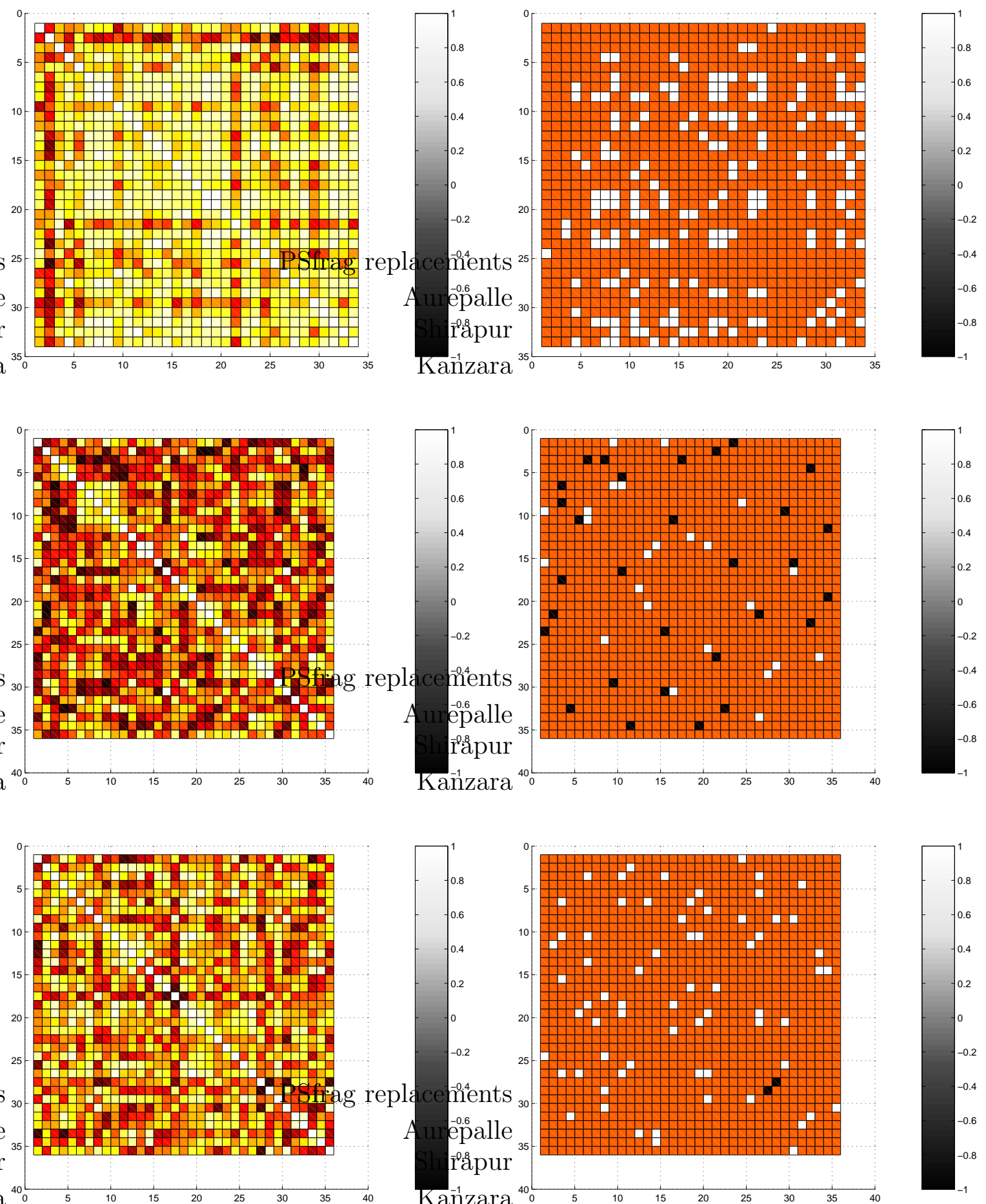

FIGURE 1. Correlations between household consumptions and Tests of significance. Figures in the first column show the complete matrix of correlation coefficients between household consumptions. The second column presents tests of the significance of these coefficients (at a 95 per cent confidence level). A black square indicates a significant negative correlation; a white sqare indicates a significant positive correlation. The first row presents data from Aurepalle; the second from Shirapur; the third from Kanzara. 
of different households, for each village. These are shown (using various shades of gray) in Figure 1. The first column of these figures indicates the degree of correlation between different households. Note that the average correlation coefficient in Aurepalle is relatively large, compared to the other two villages. In the right hand column, we report results of a bootstrap test of significance of the correlation coefficients to the left. If household consumptions were independent, then white squares would appear 2.5 per cent of the time (a false positive correlation), as would black (a false negative correlation). By this standard consumptions in Shirapur truly do appear to be nearly independent, as fewer than two per cent are significantly positive, and 2.4 per cent are negative. Households in these matrices are ordered according to their household numbers. The survey which collected these data was designed so that low household numbers were assigned to households which owned no land in the initial year (1975) of the survey, while the remaining three quarters of the sample households were selected according to a stratified sample design so that one quarter of the sampled households had land-holdings in the bottom tercile the land-holding distribution (by size of holding), a second quarter had holdings in the second tercile, and the final quarter had land-holdings in the highest tercile. Household numbers were assigned in blocks corresponding to terciles, so that the ordering of households in Figure 1 corresponds roughly to the size of their land-holdings.

More interesting patterns of correlation emerge in Aurepalle and Kanzara. In Aurepalle there are no significant negative correlations, while 17 per cent of all correlation coefficients are significant and positive. There's weaker evidence of a meaningful number of significant correlations in Kanzara, where 5.8 per cent of all correlations are significant and positive.

To a considerable degree these differences across villages simply reflect differences in aggregate risk; since there's little common time-series variation in consumptions in Shirapur, it's difficult to detect possible correlation patterns. We'd like to control for this aggregate variation, and then take a closer look at which households have significant patterns of correlation after removing purely aggregate changes in consumption (measured by the estimated $\left\{\eta_{t}\right\}$ in (2)). This amounts to looking at patterns of correlation in residuals from the regression (2). As it happens, we've already estimated the covariance matrix of these residuals; this is just the matrix $\Sigma$ we used earlier to construct a consistent estimator of the covariance matrix of our parameter estimates in (2). Figure 2 parallels Figure 1, but presents correlations for these estimated residuals.

The patterns of correlation revealed in Figure 2 aren't obviously remarkable in Shirapur and Kanzara. However, a surprising and interesting feature of the data emerges from the plots for Aurepalle. It's apparent from the figure that residuals are correlated among the first 17 households, and among the last 17; however, correlations between these two groups of households are comparatively small. This neatly divides the plot in the upper left of the figure into quadrants. So how are the first 17 households different from the final 17? The first 17 households are precisely those who either had no land or had holdings in the bottom tercile in 1975; the ICRISAT investigators intended this as a measure to capture the landless and the poorest farmers. Thus, these correlations suggest that the landless and the poorest insure among themselves, while medium and large farmers (the remaining 17 farmers) form a similar risk-sharing group.

It's of some interest to think of this result in light of the findings of Lim and Townsend (1998), who found that saving (cash and grain) was the chief mechanism used to smooth consumption in Aurepalle. Our results indicate that the two different groups we've identified 

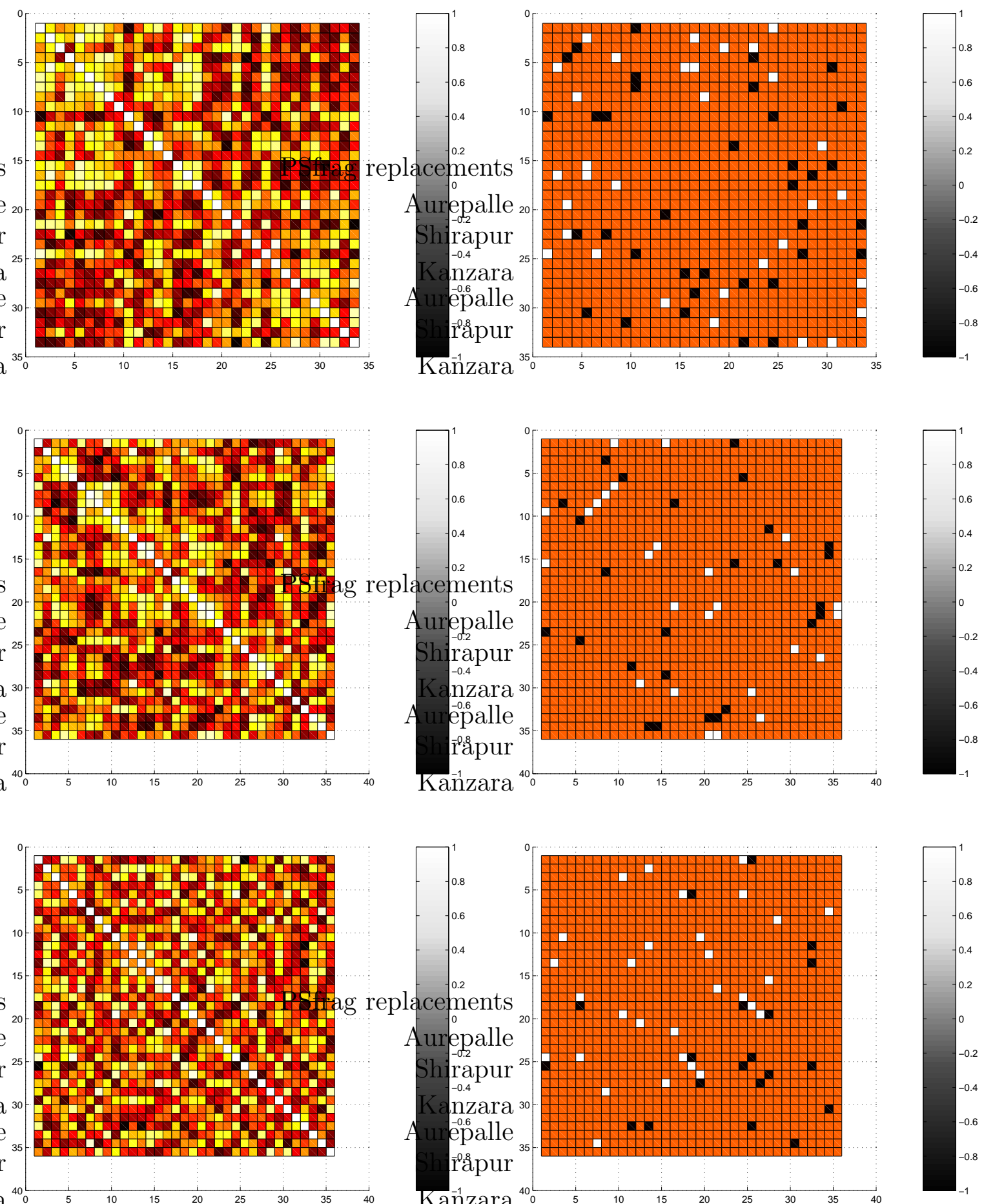

FiguRE 2. Correlations between residuals and Tests of significance. Figures in the first column show the complete matrix of correlation coefficients between the residuals from (2) for different households. The second column presents tests of the significance of these coefficients (at a 95 per cent confidence level). A black square indicates a significant negative correlation; a white square indicates a significant positive correlation. The first row presents data from Aurepalle; the second from Shirapur; the third from Kanzara. 
save at different rates. Unfortunately, our measurement of correlation in consumption residuals is silent as to the mechanism which induces this correlation, so it's not clear whether there are also contingent transfers among (but not between) the two different groups we've identified.

\section{TArgeting}

We now turn our attention to ways in which the foregoing analysis might be used to make targeted income transfers to particular households. We assume that the risk evaluation functions $\left\{U^{i}\right\}$ have been chosen to reflect the preferences of the donor. We also assume that the donor can't observe shocks faced by the household, and doesn't offer any kind of contingent transfers (doesn't act as an insurer, in other words).

Now, if it were the case that transfers made to the different households were simply consumed by that household, then targeting households to compensate each for the risk it faces would be a simple matter; one could simply estimate the risk each household faces as above, compute the necessary risk compensation, and make a non-contingent transfer $b^{i}$ to household $i$ in every period. In this way, though each household would still bear risk, each household would be indifferent between its risky consumption plus transfers and a riskless consumption with the same mean. Provided that households consumed their transfers, then such a scheme would (weakly) improve the welfare of all households while at the same time preserving, largely intact, existing incentives to save, invest, and work.

Unfortunately, in general there's no reason to suppose that a household which receives a transfer $b^{i}$ in every period will simply consume that transfer, without otherwise acting to change its intertemporal consumption profile (through saving, investment or credit markets) or making contingent transfers to other households. To take one particularly simple case, suppose that the household regards the transfer it receives in the same way that it regards other forms of income, and suppose that the simple linear allocation rule proposed above holds, so that $c_{t}^{i}=\alpha^{i}+\eta_{t}+\beta\left(x_{t}^{i}+b^{i}\right)+v_{t}^{i}$ holds, with $x_{t}^{i}$ equal to all income net of the transfer $b^{i}$. To induce the household to actually consume one additional unit in that period, one would have to transfer $1 / \beta$ to the household. However, the extra resources presumably aren't squandered; instead some share of the transfer will be given to some other household or somehow invested; this in turn will influence consumption realized by the household in other periods, or in other states.

The way in which an income transfer made to household $i$ is treated may depend both on the opportunities the household has to invest or save. Somewhat less obviously, it will also depend on prior informal arrangements the household may have made with other households. Here we give a short list of models, along with the predictions regarding the disposition of income transfers associated with each model.

4.1. Full Insurance. This is the model of Wilson (1968), Townsend (1994), and many others. The basic prediction of the model is that any collection of risk averse households will insure each other against any idiosyncratic shocks, so that household consumption at any date state can be written as a fixed, household-specific function of village aggregates, or

$$
c_{t}^{i}=f^{i}\left(z_{t}\right)
$$

In the case Townsend considers, households have Gorman-aggregable preferences, and so the relevant village aggregate is simply the total supply of the consumption good. However, even 
more general preferences deliver the result that household consumption shouldn't depend on idiosyncratic events. This arrangement may be implemented via some ex ante incomepooling scheme.

The point here, of course, is that the arrival of a donor agency making 'targeted' transfers looks just like another source of idiosyncratic shocks. In the full insurance model, households with the exponential utility functions assumed by Townsend (and no intertemporal technology) would simply pool the total transfers received by the village as a whole. Each household would receive an equal share of this windfall to supplement the consumption they would have received in the absence of the transfers. If households instead have CRRA utility functions, then they would divide the pooled transfers into unequal (but predetermined) shares. Accordingly, the effect of a targeted transfer scheme on our measure of risk would be to slightly change the aggregate risk faced by every household. There would be no effect on idiosyncratic risk (though if there was really full insurance, there would be no idiosyncratic risk to begin with).

4.2. Credit. Consider a model in which households have access to perfect credit markets, but make no arrangements to insure their consumption. These same households may or may not be constrained with respect to their borrowing, as suggested in Morduch (1995) (Lim (1992) provides a test of this hypothesis using these same data). Now, by assumption households make no contingent transfers to other households, so we need to concern ourselves only with how the transfer will affect savings and investment. Since the household had access to credit markets prior to the targeting program, it would have chosen its savings behavior to satisfy the Euler equation

$$
U^{i \prime}\left(c_{t}^{i}\right)=\mathrm{E}_{t} H_{t+j}^{i} U^{i \prime}\left(c_{t+j}^{i}\right)
$$

$j=1,2, \ldots$, where $\mathrm{E}_{t}$ denotes the household's expectations at time $t$, and where $H_{t}^{i}$ denotes the discounted realized returns on an investment of a single rupee at $t-1$. Note that here we conflate the risk evaluation function $U^{i}$ with the household's utility function, to avoid additional notation.

Now, how receipt of a transfer affects the households consumption profile hinges critically on the households expectations. If the receipt of the transfer is entirely unanticipated, the household has quadratic utility as in Hall (1978), and $H_{t}^{i}=1$ for all $t$ then household consumption will increase by exactly $b^{i}$ in every period, as this represents a change in permanent income. However, if the scheme is anticipated, household consumption will increase by less than $b^{i}$, though the earlier anticipation of the scheme may have raised consumption earlier. This raises an important practical point. If one were to canvass a village, trying to measure risk so as to implement a scheme of targeted transfers, then the very act of measurement may lead the villagers to infer that future transfers may be forthcoming. This inference, in turn, will influence consumption at the very time that one is attempting to measure it.

4.3. Private Information (Hidden Actions). We next turn our attention to a dynamic model of hidden actions described by Ligon (1998). In this model, households supply labor or make costly investments which can't be observed by others in the village. However, the total output of each household can be observed. As a consequence, in a constrainedefficient arrangement, household consumption doesn't depend directly on labor effort, but does vary with the realized output of the household. Though not strictly correct, an intuition is that observing output allows other households to infer what effort may have been, and 
to compensate the household accordingly. Thus, consumption expenditures in this model may respond to income shocks, in much the same way as the model of credit sketched in Section 4.2. However, and this is key, household compensation depends on output or other idiosyncratic shocks to the extent that these shocks provide information regarding unobserved behavior of the household, or to the extent that these shocks affect the aggregate resource constraint of the village.

As a consequence, publicly observable shocks to income, such as an observable transfer from a donor, will have no direct influence on the households' consumption expenditures, just as in the case of full insurance. In particular, suppose that all households in the village derive utility from an exponential function of consumption expenditures and disutility from an additively separable function of effort. Suppose also that household one has no private information, while household two takes some hidden labor effort $a_{t}^{2}$ to produce output $x_{t+1}^{2}$. Then in a constrained efficient arrangement, consumptions of the two households will satisfy

$$
c_{t+1}^{1}-c_{t+1}^{2}=c_{t}^{1}-c_{t}^{2}+\mu \frac{\ell_{a}\left(x_{t+1}^{2} \mid a_{t}^{2}\right)}{\ell\left(x_{t+1}^{2} \mid a_{t}^{2}\right)},
$$

where $\mu$ is a non-negative constant, the function $\ell$ is the likelihood of observing output $x_{t+1}^{2}$ given action $a_{t}^{2}$, and $\ell_{a}$ is the partial derivative of the likelihood with respect to labor effort. Note that the ratio $\ell_{a} / \ell$ is a likelihood ratio, which measures the usefulness of information $x_{t+1}^{2}$ in inferring labor effort. Adding some other random variable $b^{2}$ distributed independently of labor effort to household two's income would only increase two's consumption by an equal share of $b^{2}, b^{2} / n$. This is the same impact such a transfer would have on the consumption of every household in the village, and will be no different from the impact of making precisely the same public transfer, but to a completely different household.

4.4. Limited Commitment. Finally, we turn our attention to another dynamic model, but one in which the relevant friction is limited commitment, as in Kocherlakota (1996) or Ligon et al. (2002), and discussed at length in Platteau (1997). In this model, households make risk-sharing arrangements, but the institutions to enforce these contracts are missing or imperfect, so that any household can choose to renege on the mutual insurance arrangement ex post.

The consequences of reneging are that the household is henceforth excluded from risk sharing opportunities with all other households, and so non-trivial risk-sharing will emerge if households aren't too impatient. Households never actual renege in equilibrium. However, households who receive sufficiently large positive shocks (relative to other households) may try to renegotiate, using the (credible) threat that they will otherwise renege as leverage in their negotiations. A household which succeeds in renegotiating the risk-sharing arrangement will negotiate a larger share of consumption both in the present period and in all future periods (subject to another shock to some household possibly resulting in a subsequent renegotiation). In this way, a positive income shock even in a single period can lead to a permanent change in household expenditures, even in the absence of formal credit markets or an intertemporal technology.

The would-be donor seeking to make transfers to households in villages where risk-sharing is limited by imperfect enforcement is faced with both an opportunity and a challenge. By making a sufficiently large transfer to household $i$, the donor can effect a permanent change in the distribution of consumption expenditures. However, if the donor seeks to 
target households who are particularly vulnerable to risk, she may reduce the ability of those households to benefit from local informal insurance arrangements, and may actually increase the idiosyncratic risk the household faces. ${ }^{5}$ At the same time, the donor may reduce the effectiveness of the household's insurance of other households. This follows because a households' future demand for insurance may be reduced by transfers from the donor. If the household benefits less from informal insurance arrangements, then that makes it more likely that the household will threaten to renege in future periods, and limits the indemnity of the household both in the present period and in the future.

Finally, the point made earlier about the expectations aroused by a donor surveying a village has a parallel here. If a donor visits a village, leading locals to believe that the donor will effectively target vulnerable households in the future, then those same vulnerable households may be immediately excluded from existing risk-sharing arrangements.

\section{CONCLUSION}

In this paper we've proposed a utilitarian measure of risk, related it to existing measures of poverty, and given a method for both estimating household-specific risk and also decomposing it into aggregate and idiosyncratic components. In addition, we develop a simple estimator of risk-sharing regressions which delivers correct inference, even when estimated residuals are correlated across households (as they would be if households participated in distinct insurance networks).

We've used this technique to explore the risk faced by households in the three main Indian ICRISAT villages. Of the three villages, we infer that Aurepalle has the best intra-village insurance, but the least access to mechanisms for smoothing aggregate consumption. In contrast to Aurepalle, households in Shirapur bear almost no aggregate risk, but do face a large amount of unexplained idiosyncratic risk. Kanzara is somewhere in between, though it is the wealthiest village.

An exploration of the structure of residuals from risk-sharing regressions reveals two strikingly distinct risk-sharing networks in Aurepalle, one among the landless and smallholders; the other between medium and large holders. Risk-sharing networks are not identifiable in the other two villages, but then evidence for any effective risk-sharing in these villages is relative weak.

Finally, we discuss a sequence of models which might explain the apparently imperfect risksharing we observe in these villages, along the consequences for a benevolent donor seeking to target non-contingent transfers to particular households. In two of these three models (full insurance and dynamic moral hazard), targeting attempts seemed doomed to failure, as the "shock" of a donor making transfers is itself fully insured away. In the remaining models (credit and limited commitment) targeted transfers can change the distribution of resources in the village, but may actually tend to increase the risk targeted households face -it's possible to compensate these risk-bearing households by making them wealthier, but a more sophisticated mechanism than targeted lump-sum transfers would be necessary to reduce the risks borne by these households.

\footnotetext{
${ }^{5}$ An example of this is discussed in Attanasio and Rios-Rull (2000).
} 


\section{REFERENCES}

Arrow, K. J. (1965). Aspects of the Theory of Risk Aversion. Helsinki: Yrjö Jahnssonin säätiö.

Attanasio, O. and J.-V. Rios-Rull (2000). Consumption smoothing in island economies: Can public insurance reduce welfare? European Economic Review 44 (7), 1225-1258.

Baulch, B. and J. Hoddinott (2000). Economic mobility and poverty dynamics in developing countries. Journal of Development Studies 36(6), 1-24.

Deaton, A. (1990). On risk, insurance, and intra-village consumption smoothing. Manuscript.

Dercon, S. and P. Krishnan (2000). Vulnerability, seasonality and poverty in Ethiopia. Journal of Development Studies 36(6), 25-53.

Foster, J., J. Greer, and E. Thorbecke (1984). A class of decomposable poverty measures. Econometrica 52(3), 761-766.

Hall, R. E. (1978). Stochastic implications of the life cycle-permanent income hypothesis: Theory and evidence. Journal of Political Economy 86, 971-987.

Jalan, J. and M. Ravallion (2000). Is transient poverty different? evidence for rural China. Journal of Development Studies 36(6), 82.

Kocherlakota, N. R. (1996). Implications of efficient risk sharing without commitment. The Review of Economic Studies 63(4), 595-610.

Ligon, E. (1998). Risk-sharing and information in village economies. Review of Economic Studies 65, 847-864.

Ligon, E. and L. Schechter (2003). Measuring vulnerability. Economic Journal 113(486), C95-C102.

Ligon, E., J. P. Thomas, and T. Worrall (2002). Informal insurance arrangements with limited commitment: Theory and evidence from village economies. Review of Economic Studies 69(1).

Lim, Y. (1992). Disentangling Permanent Income from Risk Sharing: A General Equilibrium Perspective on Credit Markets in Rural South India. Ph. D. thesis, University of Chicago.

Lim, Y. and R. M. Townsend (1998). General equilibrium models of financial systems: Theory and measurement in village economies. Review of Economic Dynamics 1(1), 59118.

Morduch, J. (1995, Summer). Income smoothing and consumption smoothing. Journal of Economic Perspectives 9(3), 103-114.

Newey, W. K. and K. D. West (1987). Hypothesis testing with efficient method of moments estimation. International Testing with Efficient Method of Moments Estimation 28(3), $777-787$.

Platteau, J.-P. (1997, August). Mutual insurance as an elusive concept in traditional rural societies. Journal of Development Studies 33(6), 764-796.

Ravallion, M. (1988). Expected poverty under risk-induced welfare variability. Economic Journal 98(393), 1171-1182.

Rothschild, M. and J. E. Stiglitz (1970). Increasing risk: I. A definition. Journal of Economic Theory 2, 225-243.

Townsend, R. M. (1994). Risk and insurance in village India. Econometrica 62 (3), 539-591.

Wilson, R. (1968, January). The theory of syndicates. Econometrica 36, 119-132. 